\title{
Effects of 8 weeks oligofructose supplementation on appetite and body weight in overweight and obese adults
}

\author{
N. M. Daud ${ }^{1}$, N. Ismail ${ }^{1}$, E. L. Thomas ${ }^{2}$, S. Scholtz ${ }^{2}$, G. Durighel ${ }^{2}$, J. A. Fitzpatrick ${ }^{2}$, \\ A. P. Goldstone ${ }^{2}$, J. D. Bell ${ }^{2}$, P. R. Bech ${ }^{1}$, E. Chambers ${ }^{1}$, N. Chhina ${ }^{2}$, M. A. Ghatei ${ }^{1}$, \\ C. Pedersen ${ }^{1}$ and G. S. Frost \\ ${ }^{1}$ Division of Diabetes, Endocrinology and Metabolism and ${ }^{2}$ Metabolic and Molecular Imaging Group, MRC Clinical \\ Sciences Centre, Imperial College London, Hammersmith Hospital, London W12 ONN, UK
}

Supplementing the diet with fermentable carbohydrate (FC) has been suggested to reduce appetite and body weight. Recent findings have demonstrated that inulin-type fructans reduce food intake, body weight and fat mass in rodents ${ }^{(1,2)}$. However, the effects in humans are inconclusive. This study investigated the effects of FC [oligofructose (OFS)] on appetite profiles, satiety hormone concentration, colonic fermentation, energy intake and body weight following 8 weeks supplementation in overweight and obese adults.

22 healthy subjects, male ( $n$ 6), female ( $n$ 16), mean age 30 (SD 8 ) years with mean BMI 31.1 (SD 3.4$) \mathrm{kg} / \mathrm{m}^{2}$ completed a randomised, double-blind, parallel study comprised of a 2 week run-in period followed by $30 \mathrm{~g}$ fibre/day supplementation of either OFS ( $n$ 12) or placebo (cellulose + maltodextrin) ( $n$ 10) for 6 weeks. On day 0 (baseline) and day 56 (post-supplementation) subjects were served a standardised breakfast and lunch. Throughout a 420 min postprandial period blood samples were taken to determine peptide YY (PYY) concentrations and visual analogue scales were used to assess subjective appetite feelings. Breath hydrogen was also recorded as a marker of colonic fermentation. Following $420 \mathrm{~min}$ participants were served an ad libitum meal to measure energy intake.

Dietary supplementation with OFS significantly decreased hunger $(P=0.016)$, motivation to eat $(P=0.027)$ and significantly increased breath hydrogen $(P=0.017)$ on day 56 compared with cellulose treatment. However, subjective fullness $(P=0.187)$, energy intake $(P=0.344)$ and PYY $(P=0.145)$ were not affected by OFS treatment. Supplementing the diet with OFS had no effect on body weight compared with cellulose $(P=0.461)$

\begin{tabular}{|c|c|c|c|c|}
\hline \multirow[b]{3}{*}{ Parameters } & \multicolumn{2}{|c|}{ Oligofructose } & \multicolumn{2}{|c|}{ Cellulose } \\
\hline & \multicolumn{2}{|c|}{ Change from baseline } & \multicolumn{2}{|c|}{ Change from baseline } \\
\hline & Mean & SE & Mean & SEM \\
\hline Fullness (tAUC) (cm min) & 304.5 & 120.9 & 190.2 & 230.4 \\
\hline Hunger (tAUC) $(\mathrm{cm} \mathrm{min})$ & $-664.4^{*}$ & 146.2 & -12.1 & 258.7 \\
\hline Motivation to eat (tAUC) ( $\mathrm{cm}$ min) & $-647.1^{*}$ & 176.5 & -99.0 & 201.4 \\
\hline PYY (tAUC) (pmol min/l) & 578.3 & 320.3 & 86.1 & 308.6 \\
\hline Breath hydrogen (tAUC) (ppm min) & $4031.0^{*}$ & 1357.0 & 561.5 & 292.9 \\
\hline Energy intake (kcal) & -113.0 & 33.8 & -142.3 & 67.9 \\
\hline Body weight $(\mathrm{kg})$ & 0.4 & 0.5 & 0.5 & 0.5 \\
\hline
\end{tabular}

Previous studies that have reported a positive effect of OFS on energy intake and body weight have used a digestible carbohydrate (maltodextrin) as a control ${ }^{(3,4,5)}$. To our knowledge, this is the first study to compare the effects of OFS on appetite regulation with a nondigestible carbohydrate. In conclusion, supplementing $30 \mathrm{~g} /$ day OFS into the diet reduces subjective appetite and increases breath hydrogen. However, there was no significant effect on PYY release, energy intake and body weight compared to cellulose.

1. Cani PD, Dewever C \& Delzenne NM (2004) Br J. Nutr 92, 521-526.

2. Cani PD, Neyrinck AM, Maton N et al. (2005) Obes Res 13, 1000-1007.

3. Verhoef SP, Meyer D \& Westerterp KR (2011) Br J. Nutr 17, 1-6.

4. Parnell JA \& Reimer RA (2009) Am J. Clin Nutr 89, 1751-1759.

5. Cani PD, Joly E, Horsmans Y et al. (2006) Eur J. Clin Nutr 60, 567-572. 